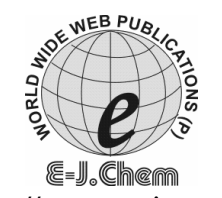

http://www.e-journals.net

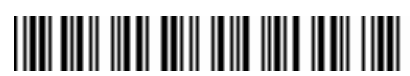

ISSN: 0973-4945; CODEN ECJHAO

E-Journal of Chemistry

Vol. 5, No.3, pp. 453-460, July 2008

\title{
Determination of Free Levels of Cinitipride in Human Plasma by Liquid Chromatography-Tandem Mass Spectrometry
}

\author{
SHIKHA M.N.ROY*, SANTOSH. M. YETAL, SANGITA V.CHAVAN, \\ VARAD. R PRADHAN and SANTOSH S. JOSHI \\ Department of Chemistry, G.N.Khalsa College, \\ Matunga, Mumbai-400 019, India. \\ santosh_yetal@yahoo.com
}

Received 5 October 2007; Accepted 20 December 2007

\begin{abstract}
A rapid, sensitive and specific method to quantify cinitapride in human plasma using risperidone as the internal standard is described. Sample preparation involved simple solid phase extraction procedure. The extract was analyzed by high performance liquid chromatography coupled to electrospray tandem mass spectrometryAPI-4000 (LC-MS/MS). Chromatography was performed isocratically on Thermo Hypurity $\mathrm{C}_{18}$ analytical column, $(50 \mathrm{~mm} \mathrm{X}$ $4.6 \mathrm{~mm}, 5 \mu \mathrm{m}$ i.d.). The assay of cinitapride was linear calibration curve over the range $20.118 \mathrm{pg} \mathrm{mL}^{-1}$ to $2011.797 \mathrm{pg} \mathrm{mL}^{-1}$. Plasma concentrations of cinitapride were determined by LC-MS/MS with a limit of quantification of $20.118 \mathrm{pg} \mathrm{mL}^{-1}$ that allowed an appropriate characterization of the pharmacokinetic profile of cinitapride at the therapeutic dose. The method was successfully applied to the bioequivalence study of cinitapride tablet $(1.0 \mathrm{mg})$ administered as a single oral dose.
\end{abstract}

Keywords: Cinitapride, Human plasma and LC-MS/MS

\section{Introduction}

Cinitapride, chemically 4-amino- $N$-[3-(Cyclohexan-1-yl-methyl)-4-piperidinyl]-2-ethoxy-5nitrobenzamide has the molecular formula $\mathrm{C}_{21} \mathrm{H}_{30} \mathrm{~N}_{4} \mathrm{O}_{4}$ and molecular weight ${ }^{1} 402.49$ g.mol $^{-1}$.<smiles>CCOc1cc([N+](=O)[O-])c([N+](=O)[O-])cc1C(=O)NC1CCN(CC2CC=CCC2)CC1</smiles> 
Cinitapride is a drug that has against action to the serotoninergic 5-HT2 and D2 dopaminergic receptors that has been indicated in the gastroesophageal reflux and in the functional disorders of gastrointestinal motility treatment. The therapeutic effect of cinitapride lies on the capacity of increasing lower esophageal sphincter tone and has strong gastrokinetic activity, which generates significant increases in the gastric emptiness; besides, through the serotoninergic system it stimulates the intestinal activity. The use of cinitapride is efficient and safe in treatment of patients with disorders in the gastric emptiness related to gastroesophageal reflux and functional dyspepsia as well as in individuals that present irritable bowel syndrome with constipation and abdominal pain ${ }^{3-10}$. For determination polarographic and LC-MS/MS method has been used ${ }^{2,14}$. Here we present a fast, sensitive and selective method for measuring plasma cinitrapride using LC-MS/MS with positive ion electrospray ionization using multiple reaction-monitoring (MRM) mode to quantify cinitapride in human plasma using respridone as the internal standard. This method was employed in a bioequivalence study to compare the rate and extent of absorption of cinitapride $1 \mathrm{mg}$ tablets under fasting conditions in 12 healthy, adult, male subjects in a randomized crossover study

\section{Experimental}

Working standard of cinitapride hydrogen tartrate was obtained from cadila healthcare Limited, Ankleshwar, India. Working standard of risperidone was obtained from Jubilant Organosys Limited, Mysore, India. Methanol and acetonitrile of HPLC grade were used of J.T. Baker; Ammonium acetate, ortho phosphoric acid and acetic acid of HPLC grade were obtained from BDH. Merck HPLC grade water was used.

\section{Instrumentation and chromatographic conditions}

The mass spectrometer API 4000 (SCIEX) with Turbo Ionspray source coupled with LC model Shimadzu LC-20AD system (Kyoto, Japan), equipped with two pumps, a vacuum degasser and an autosampler (SIL-HTc) were used in the study. Chromatographic separation was performed on Thermo Hypurity $\mathrm{C}_{18}, 5 \mu \mathrm{m}$ analytical column $(50 \mathrm{~mm} \mathrm{x}$ $4.6 \mathrm{~mm}$ i.d.) at ambient temperature. The mobile phase was consisted of acetronitrile and $2 \mathrm{mM}$ ammonium acetate in a ratio of $90: 10(\mathrm{v} / \mathrm{v})$. Analyst 1.4 software package was used for instrument control and data acquisition. The ion spray voltage was set at $5.5 \mathrm{kv}$ and source temperature at $500^{\circ} \mathrm{C}$. The collision activation dissociation (CAD) was set at 4.0 , using nitrogen as the collision gas. Instrument was set up in multiple reactions monitoring (MRM), monitoring the transitions for cinitapride $403.3>209.0$ and respiridone $411.4>191$.

\section{Preparation of the stock solution and calibration and quality control samples}

Master stock solutions of cinitapride $\left(1005.899 \mu \mathrm{g} \mathrm{mL}^{-1}\right)$ and respiridone $\left(996.867 \mu \mathrm{gmL}^{-1}\right)$ were prepared separately in methanol. Further intermediate solution were used as $10.059,1.006,0.101$ and $0.010 \mu \mathrm{g} \mathrm{mL}^{-1}$. For calibration curve and quality control sample, series of working calibration standard solutions at concentrations of 402.359, 804.719, 2011.797, 4023.595, 8047.190, 16094.380, 24141.570, 32188.760 and $40235.950 \mathrm{pg} \mathrm{mL}^{-1}$ were prepared by appropriate dilution of its stock with diluent. Similarly, low, medium and high quality control working standard solutions of 1207.532, 12075.318 and 30188.296 $\mathrm{pg} \mathrm{mL} \mathrm{m}^{-1}$ respectively were prepared in diluent from another master stock solution of cinitapride $\left(1006.277 \mathrm{\mu g} \mathrm{mL}^{-1}\right)$. Working internal standard solution $\left(1.994 \mathrm{pg} \mathrm{mL}^{-1}\right)$ was also prepared in diluent. Diluent used for preparation of working solution is the mixture of methanol and water in the ratio 60: $40(\mathrm{v} / \mathrm{v})$. Stock solution was stored at $4-8^{0} \mathrm{C}$ and used 
within 30.0 days. Calibration curves were prepared by spiking blank plasma at concentration of $20.118,40.236,100.590,201.180,402.359,804.719,1207.078,1609.438$ and 2011.797 pg mL $\mathrm{m}^{-1}$ and quality control $60.377,603.766$ and $1509.415 \mathrm{pg} \mathrm{mL}^{-1}$ of cinitapride

\section{Sample preparation}

All frozen human plasma sample were previously thawed at ambient temperature and centrifuged at $15000 \mathrm{x}$ g for $5.0 \mathrm{~min}$. Five hundred micro liters of sample human plasma were introduced into $1.5 \mathrm{~mL}$ of eppendrof tube followed by $50.00 \mu \mathrm{L}$ of internal standard $(1.994 \mathrm{pg}$ $\mathrm{mL}^{-1}$ ) solution and $100 \mu \mathrm{L}$ of $1.0 \%$ ortho phosphoric acid. The contents of the tube were vortexed for 30 seconds. Solid phase extraction (SPE) was used to extract drug and internal standard from human plasma. Extraction cartridges (Phenomenex Strata-X, $33 \mu \mathrm{m}$ polymeric reversed phase, $30 \mathrm{mg} / 1 \mathrm{~mL}$ ) were placed on positive pressure processor (Ezypress ${ }^{\circledR} 48$ ) and equilibrated with $1.0 \mathrm{~mL}$ methanol followed by $1.0 \mathrm{~mL}$ of $0.1 \% \mathrm{v} / \mathrm{v}$ acetic acid. Spiked plasma sample was loaded into the cartridges and drawn by applying pressure. The cartridge was then washed by the $0.1 \% \mathrm{v} / \mathrm{v}$ acetic acid followed by $1.0 \mathrm{~mL}$ of water twice. Elution was done with $0.5 \mathrm{~mL}$ of mobile phase and injected into the LC-MS/MS system.

\section{Linearity}

A calibration line is a curve showing the relation between the concentration of the analyte in the sample and the detected response. It is necessary to use a sufficient number of standards to define adequately the relationship between response and concentration. The relationship between response and concentration must be demonstrated to be continuous and reproducible. The number of standards to be used will be a function of the dynamic range and nature of the concentration-response relationship. In cinitapride, nine concentrations (excluding blank values) define the standard curve. The difference between the observed $y$-value and fitted y-value is called a residual. A linear least-squares regression with a weighting index of $1 / \mathrm{x}^{2}$ was performed on the peak area ratios of cinitapride drug to internal standard $v s$ concentrations of 20.118, 40.236, 100.590, 201.180, 402.359, 804.719, $1207.078,1609.438$ and $2011.797 \mathrm{pg} \mathrm{mL}^{-1}$ to generate a calibration curve ${ }^{13}$.

\section{Recovery}

Extraction recoveries of cinitapride in human plasma were determined by comparison of response (area) from extracted QC level samples containing known amount of drug and internal standard to those from unextracted samples directly spiked with the same amount of the QC standard solutions of the respective concentration.

\section{Stability}

To determine the influence of temperature and surrounding on the stability of drugs in plasma matrix, the plasma quality control samples spiked with drug and analyzed under different condition: The basic fundamental parameter of the method validation were determined by stock solution stability (kept the stock solution at $4-8^{0} \mathrm{C}$ ) for a month, freezethaw stability at three cycle, short-term stability, an autosampler and long-term stability. For freeze-thaw stability, QC plasma samples were subjected to three cycles from $-20^{\circ} \mathrm{C}$ to room temperature. Short term bench top stability was performed by placing samples on the bench top at ambient temperature for $24 \mathrm{~h}$. Autosampler stability was assessed by placing processed QC samples in an autosampler at $10^{\circ} \mathrm{C}$ for $24 \mathrm{~h}$, and long term stability was evaluated by freezing QC samples at $-20^{\circ} \mathrm{C}$ for a month, then comparing the concentration with those of QC before the storage period ${ }^{13}$. 


\section{Bioequivalence study}

The study has open label, randomized, two-period, two-treatment, two-sequence single dose crossover design. Written notification of approval was obtained from the independent Ethics Committee (IEC) and given to the investigator before starting the study, which was performed according to the directives of the declaration of Helsinki for biomedical research in human's announcements for the principles for correct implementation of clinical trials as well as the ICH GCP guidelines. Before enrollment, all subjects were comprehensively informed about the trial (procedures, pharmacological effects, adverse events, consequences, risks and hazards), and about their right to withdraw at any time without specifying reasons. All subjects gave their written informed consent prior to participation. Twelve normal healthy male subjects were enrolled. All the subjects were mating the inclusion/exclusion criteria. Plasma samples from subjects who completed both periods were analyzed in same analytical batch run. Subjects have assigned subject numbers serially with 01 to 12 as per there reporting time (subject check-in) of the subjects in the clinical pharmacology Unit. This number would identify the subject and determine the sequence of drug administration as described in the randomization schedule. Study has a two-period, two-sequence bioequivalence study. In each period, subjects were administered either test or reference product, according to the randomization schedule. The test and reference product has assigned with the randomization code (A or B). The randomization schedule was prepared by the biostatistician by using SAS software, Version 8.2. To compare the rate and extent of absorption of cinitapride $1 \mathrm{mg}$ tablets; test product i.e. cinitapride $1 \mathrm{mg}$ tablets, (Manufactured by Cadila Healthcare Limited, India) and reference product, i.e. cidine $1 \mathrm{mg}$ (Cinitapride $1 \mathrm{mg}$ ) tablet, (Manufactured by Recordati, Spain) under fasting conditions in 12 healthy adult male subjects in a randomized crossover study, to monitor the safety and tolerability of a single dose of cinitapride $1 \mathrm{mg}$ in healthy subjects. Blood samples $(7 \mathrm{~mL})$ were collected in centrifuge tubes containing $0.1 \mathrm{~mL}$ of EDTA (10\%) 0 hour (within 1 hour pre-dosing) and at the following times after drug administration, $0.50,1.00,1.50,2.00,2.50,3.00,4.00,5.00,6.00,8.00$, 12.00 , and 24.00 hours (13 samples), within 2 minutes of scheduled sampling time, post dosing on both the study periods. After every blood sample collection $0.5 \mathrm{~mL}$ of normal saline was injected to the i.v. cannula. Also, before every blood sample collection $0.1 \mathrm{~mL}$ of normal saline present in the i.v cannula was discarded. Approximately $204.6 \mathrm{~mL}$ (including $20 \mathrm{~mL}$ for clinical laboratory tests and $2.6 \mathrm{~mL}$ as total volume discarded before each sampling) of total blood was drawn from each subject, for both the periods. Collected sample were centrifuged at $3200 \mathrm{rpm}$ for 10 minutes at $10^{\circ} \mathrm{C}$. Collected sample were transferred to appropriate size polypropylene screw top labeled vials. Plasma samples were placed in deep freezer maintained ${ }^{12}$ at $-20 \pm 5^{\circ} \mathrm{C}$.

\section{Pharmacokinetics analyses}

Analysis of variance (ANOVA) is performed $(\alpha=0.05)$ on the log-transformed pharmacokinetic parameters $\mathrm{C}_{\max }, \mathrm{AUC}_{0-\mathrm{t}}, \mathrm{AUC}_{0 \text {-inf. }}$ The analysis of variance model is included sequence, subjects nested within sequence, period and treatment as factors. Each analysis of variance is also including calculation of least-square means, adjusted differences between formulation means and the standard error associated with these differences. The significance of the sequence effect is tested using the subjects nested within the sequence as an error term. The $90 \%$ confidence intervals for the difference between treatments are calculated using two one-sided test for log-transformed $\mathrm{C}_{\max }, \mathrm{AUC}_{0-\mathrm{t}}, \mathrm{AUC}_{0 \text {-inf }}$ and intervals is expressed as a percentage it's exponential. The power (i.e. probability of detecting a $20 \%$ difference relative to the reference treatment at the $5 \%$ significance level using a t-test under the null hypothesis of zero difference) is calculated for $\log$ transformed $\mathrm{C}_{\max }, \mathrm{AUC}_{0-\mathrm{t}}, \mathrm{AUC}_{0 \text {-inf. }}$. 
The geometric least square mean ratios and the $90 \% \mathrm{CI}$ of $\mathrm{C}_{\max }, \mathrm{AUC}_{0-\mathrm{t}}, \mathrm{AUC}_{0 \text {-inf }}$ for reference and test formulations are considered for evaluating bioequivalence. To be considered bioequivalent $90 \% \mathrm{CI}(\%)$ should lay between following ${ }^{11}$ acceptances ranges 80-125.

\section{Results and Discussion}

Linearity was determined to assess the performance of the method. Regression coefficient ( $\mathrm{r}$ ) greater than 0.99 and low CV (\%) indicated the repeatability of the method. The extraction recovery of developed method determined at low, medium and high QCs levels was $55.91 \%$, $52.75 \%$ and $55.12 \%$. Absolute mean \% recovery of the cinitapride and internal standard risperidone was found to be $54.59 \%$ and $69.76 \%$ respectively. In this assay, the inter day precision was $9.99 \%, 8.30 \%, 6.47 \%$ and intra day precision was $3.88 \%, 8.45 \%, 5.18 \%$ at low, medium and high QCs levels for cinitapride .The inter day accuracy was $105.00 \%, 99.99 \%$, $105.78 \%$ and intra day accuracy was $102.83 \%, 100.33 \%, 107.76 \%$ at low, medium and high QCs levels for cinitapride. Table 1, 2 and 3 results demonstrated that the values are within the acceptable range and method is linear reproducible, accurate and precise.

Table 1. Data of inter day and intra day precision and accuracy.

\begin{tabular}{|c|c|c|c|c|c|c|c|}
\hline \multirow[b]{2}{*}{$\begin{array}{l}\mathrm{QC} \\
\text { level }\end{array}$} & \multirow[b]{2}{*}{$\begin{array}{l}\text { Nominal conc. } \\
\qquad \mathrm{pg} \mathrm{mL}^{-1}\end{array}$} & \multicolumn{3}{|c|}{ Inter day precision and accuracy } & \multicolumn{3}{|c|}{ Intra day precision and accuracy } \\
\hline & & $\begin{array}{l}\text { Observed mean } \\
\text { calculated } \\
\text { conc. pg mL }\end{array}$ & $\begin{array}{c}\text { \%Assay, } \\
n=12\end{array}$ & $\begin{array}{c}\% \mathrm{CV} \\
\mathrm{n}=12\end{array}$ & $\begin{array}{c}\text { Observed mean } \\
\text { calculated conc. } \\
\text { pg mL }^{-1}\end{array}$ & $\begin{array}{l}\% \text { Assay, } \\
\mathrm{n}=12\end{array}$ & $\begin{array}{c}\% \mathrm{CV}, \\
\mathrm{n}=12\end{array}$ \\
\hline LQC & 60.377 & 58.036 & 96.12 & 9.15 & 61.765 & 102.30 & 4.42 \\
\hline MQC & 603.766 & 585.829 & 97.03 & 6.23 & 618.227 & 102.40 & 2.18 \\
\hline HQC & 1509.415 & 1434.744 & 95.05 & 5.67 & 1506.521 & 99.81 & 1.23 \\
\hline
\end{tabular}

Table 2. Data of correlation coefficient(r)

\begin{tabular}{cccc}
\hline Calibration curve & Slope & Intercept & Regression \\
\hline 1 & 0.000581 & 0.00376 & 0.9998 \\
2 & 0.000587 & 0.0032 & 0.9994 \\
3 & 0.000837 & 0.00833 & 0.9995 \\
Mean & 0.000668333 & 0.005096667 & 0.999566667 \\
\hline
\end{tabular}

Table 3. Data of standard curves $(n=3)$

\begin{tabular}{ccccc}
\hline Level & $\begin{array}{c}\text { Nominal } \\
\text { concentration pg mL }\end{array}$ & $\begin{array}{c}\text { Observed mean calculated } \\
\text { concentration } \mathrm{pg} \mathrm{mL}^{-1}\end{array}$ & \% Accuracy & $\% \mathrm{CV}$ \\
\hline 1 & 20.118 & 20.243 & 100.62 & 3.89 \\
2 & 40.236 & 39.988 & 99.38 & 7.77 \\
3 & 100.590 & 101.962 & 101.36 & 3.90 \\
4 & 201.180 & 196.076 & 97.46 & 1.57 \\
5 & 402.359 & 402.512 & 100.04 & 2.92 \\
6 & 804.719 & 837.977 & 104.13 & 1.12 \\
7 & 1207.078 & 1160.306 & 96.13 & 2.66 \\
8 & 1609.438 & 1610.751 & 100.08 & 1.17 \\
9 & 2011.797 & 2027.701 & 100.79 & 1.40 \\
\hline
\end{tabular}

Six different sources of normal heparin blank plasma, three different sources hemolysed and three different sources lipimic samples were extracted and analyzed for the assessment of potential interference with endogenous substances. The apparent response at the retention time of cinitapride was compared to the lower limit of quantification sample $\left(20.118 \mathrm{pg} \mathrm{mL}^{-1}\right.$ Figure 1 and 2 shown representatitive chromatogram of specificity. The average $\%$ difference obtained is less than $20 \%$. 
PB-1-Ciaitapride (Unknown) 403.3/209.0 amu

Area: 392 counts Height: 57.928 cps RT: 2.07 min

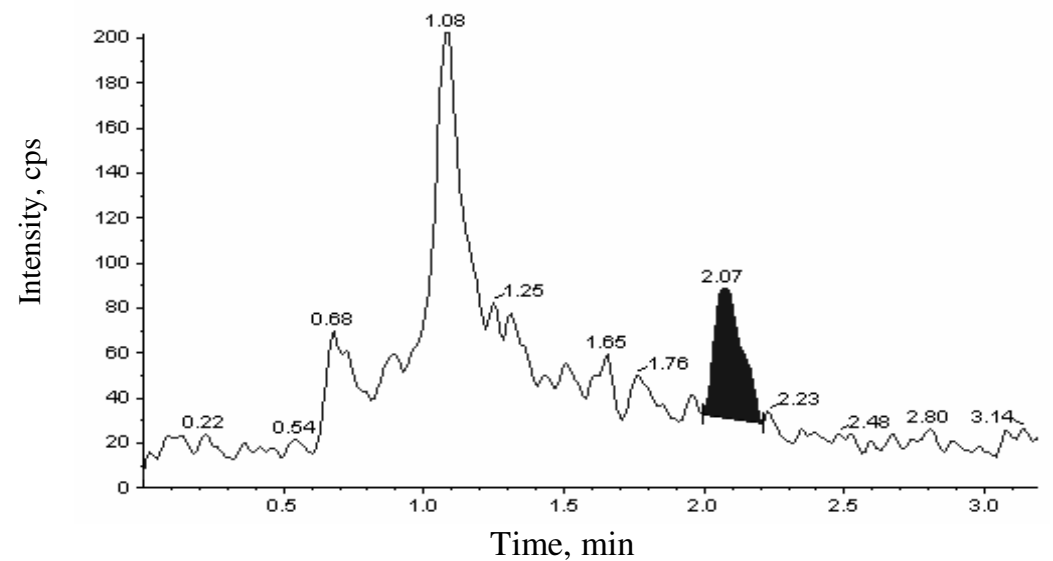

Figure 1. Representative chromatograms plasma blank for cinitapride drug

LlOQ-1-Cinitapride (Unknown) 403.3/209.0 amu

Area: 3595 counts Height: 494.833 cps RT: $2.08 \mathrm{~min}$

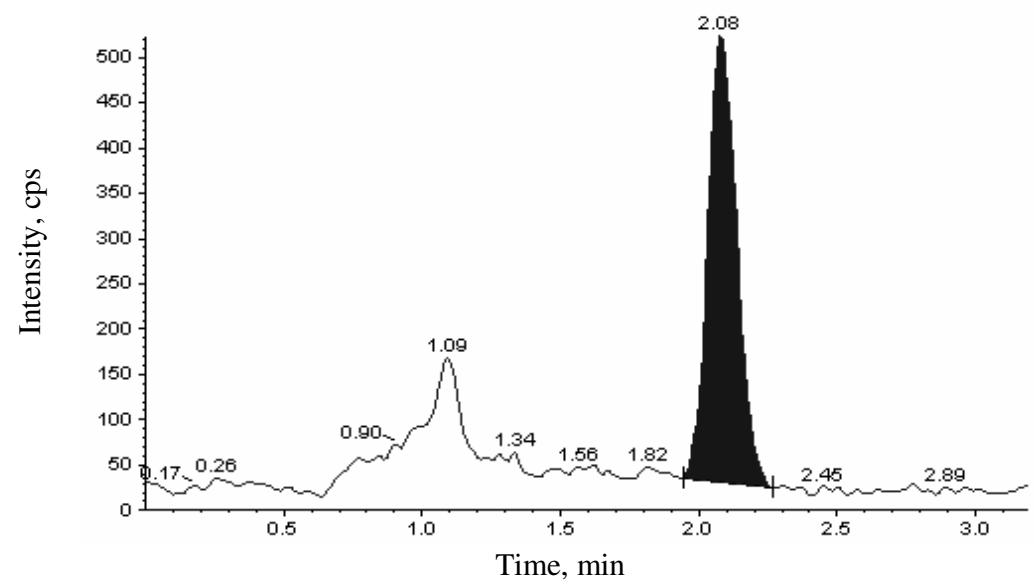

Figure 2. Representative chromatograms plasma spiked with cinitapride drug at the lower limit of quantification

Drug stability after three freeze and thaw cycles was performed at LQC and HQC concentrations and the percent bias was evaluated to be as low as $2.56 \% \& 3.48 \%$ respectively on comparison with freshly prepared samples. Bench top stability was done for $12 \mathrm{~h}$ at LQC and HQC concentrations and the percent bias calculated by comparing with freshly prepared sample was found to be $1.02 \% \&-1.68 \%$ respectively. Autosampler stability was also done for $24 \mathrm{~h}$ at the two QC concentrations LQC and HQC respectively. The percent bias was found to be about $-2.56 \% \&-3.48 \%$ respectively. Long term stability was evaluated the percent bias about $5.26 \% \& 4.82 \%$ respectively by freeze two QC concentrations LQC and $\mathrm{HQC}$ respectively samples at $-20^{\circ} \mathrm{C}$ for a month, then comparing the concentration with those of QC before the storage period. 
The primary object of the designed study was the assessment of the pharmacokinetic after single doses of cinitapride $1.0 \mathrm{mg}$ tablet and safety of the study treatment were also evaluated. The plasma concentrations of cinitapride are determined by LC-MS/MS technique. The electrospray ionization of cinitapride and risperidone produced the abundant protonated molecules ([MH+]) at $\mathrm{m} / \mathrm{z} 403.3$ and 411.4 , respectively under positive ionization conditions, without any adduct formation. For proposed validated analytical method acceptance criteria is achieved for accuracy and precision for the validation of QC sample over the range of the standards. As per guideline recovery of the analyte need not be $100 \%$, but the extent of recovery of an analyte and internal standard should be consistent, precise and reproducible. Overall precision and accuracy of the proposed validated method meets the acceptance criteria.

\section{Application of method}

This method has been successfully applied to the bioequivalence study of cinitapride $(1 \mathrm{mg}$ tablet) in twelve healthy volunteers. The mean concentration versus time profile after a single oral dosing of Cinitapride tablet $(1 \mathrm{mg})$ in twelve healthy volunteers is shown in Figure 3. The Table 4 shows calculated pharmacokinetic parameter $C_{\max }, T_{\max }, \mathrm{AUC}_{\mathrm{t}}$ and $\mathrm{AUC}_{\mathrm{inf}}$ of cinitapride.

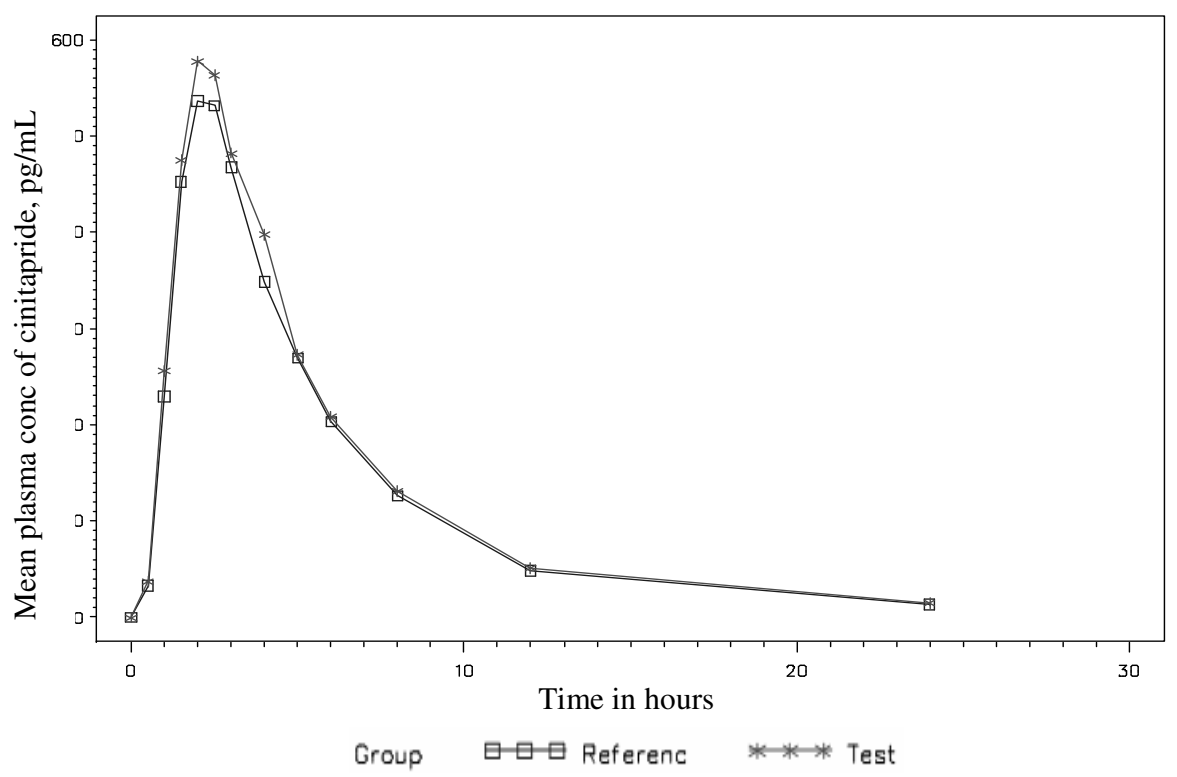

Figure 3. Mean concentration versus time profile

Table 4. Pharmacokinetic parameter results

\begin{tabular}{cccc}
\hline \% Ratio for untransformed PK & parameters based on LS Mean \\
\hline PK Parameters & Test & Reference & \% Ratio \\
\hline Cmax, pg & 615.48 & 561.52 & 109.61 \\
Tmax & 2.21 & 2.17 & 101.84 \\
AUCt & 3100.99 & 2930.62 & 105.81 \\
AUCinf & 3282.54 & 3105.16 & 105.71 \\
\hline
\end{tabular}




\section{Conclusion}

A rapid, sensitive and reliable LC-MS/MS method for the determination of cinitapride has been successfully developed and validated using solid phase extraction. This assay method demonstrated acceptable sensitivity, recovery, precision, accuracy and stability. The validated method was successfully applied to assay human plasma samples from the bioequivalence study of cinitapride.

\section{References}

1 Article: An improved process for the preparation of Cinitapride Hydrogen Tartarate Application 341/MUM/2004 published, 2007-03-02, filed, 2004-03-19

2 Gonzalez M I, Gonzalez P C and Blanco Lopez M A, Analytica Chimica Acta, 1998, 368(1), 175-181.

3 Alarcon de la Lastra C, La Casa C, Martin M J and Motilva V, Inflammation Research, 1998, 47(3),131-136.

4 Alberti J, Alvarez M, Navarro J and Salva M, Metabolismo in vitro de cinitaprida en presencia de microsomas hepáticos humanos. Identificación del citocromo P450 responsable del etabolismo de cinitapride. Data on File, Almirall Prodesfarma S A, 2000.

5 Crumb W J, Herg blocking profile of SD-33 (cinitapride). Data on File, Almirall Prodesfarma, S A, 2000.

6 De Graeve J, Identification by mass spectrometry of the chemical structures of in vivo human metabolites of cinitapride - Evaluation of their plasmatic and urinary elimination profiles. Data on File, Almirall Prodesfarma, 2001.

$7 \quad$ Fernandez A G and Roberts D J, Drugs Fut. 1991, 16 885-92.

8 Massingham R, Bou J and Roberts D J, J. Auton Pharmacol, 1985, 5, 41- 53.

9 Ames.Tonini M, De Ponti F, Di Nucci A and Crema F, Aliment Pharmacol Ther, 1999, 13, 1585-1591.

10 Totah RA and Rettie A E, Clin Pharmacol Ther. 2005, 77, 341-352.

11 U. S. Food and Drug Administration. Guidance for Industry: Statistical Approaches to Establishing Bioequivalence, January 2001.

12 Department of Health Services, Food and Drug Administration.U.S., January 19, 2001, 66(13),5515-5517.

13 Guidance for Industry: Bioanalytical Method Validation. U.S. Department of Health and Human Services. FDA. CDER. CVM. May 2001.

14 Marta Robert, Miquel Salva, Rosa Seggara, Marco Pavesi, Ramon Esdri, David Roberts and Georg Golor, Drug metabolism and disposition, Fast forward, April2007. 


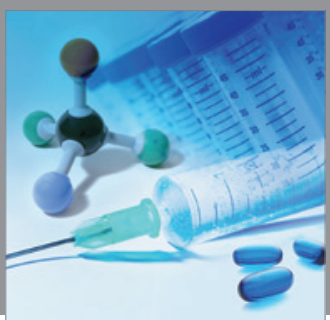

International Journal of

Medicinal Chemistry

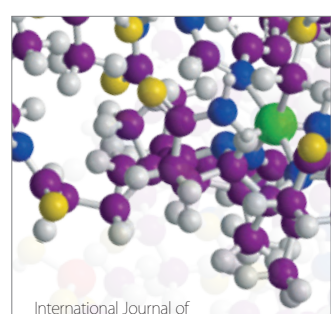

Carbohydrate Chemistry

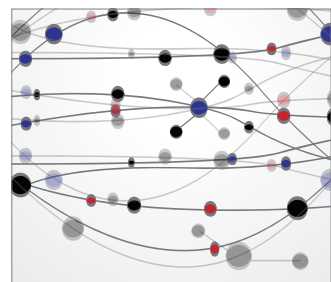

The Scientific World Journal
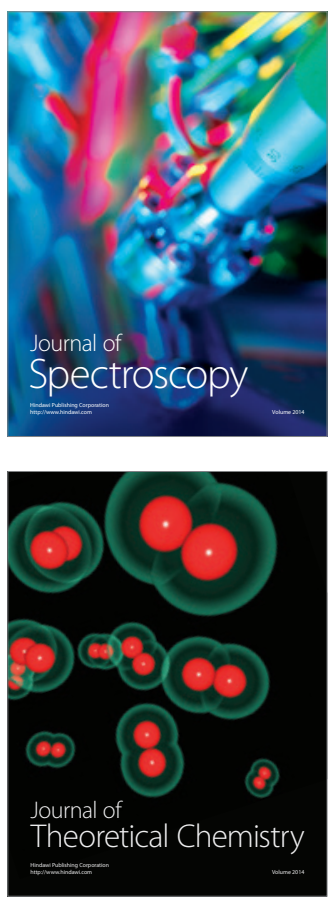
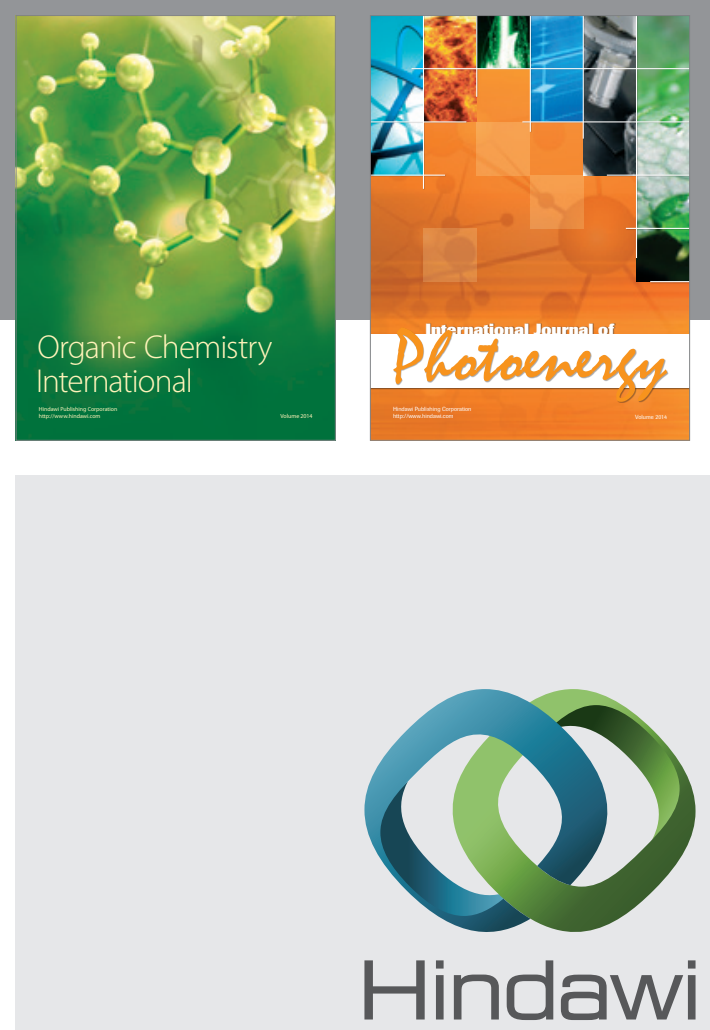

Submit your manuscripts at

http://www.hindawi.com
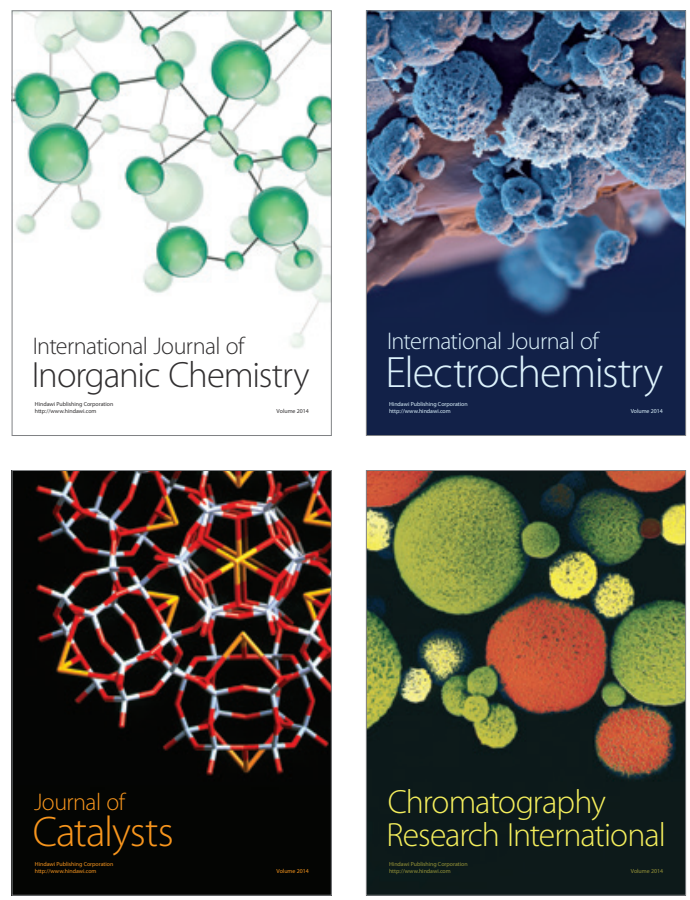
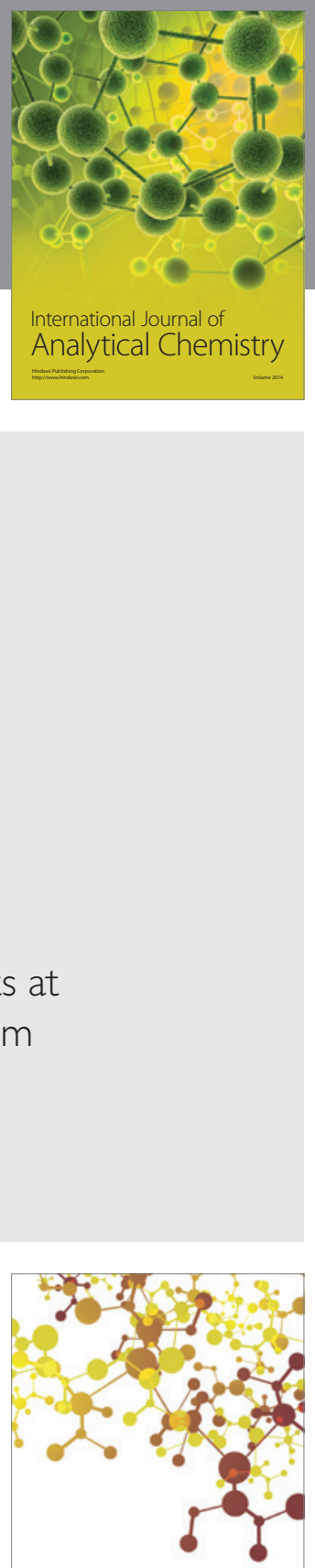

Journal of

Applied Chemistry
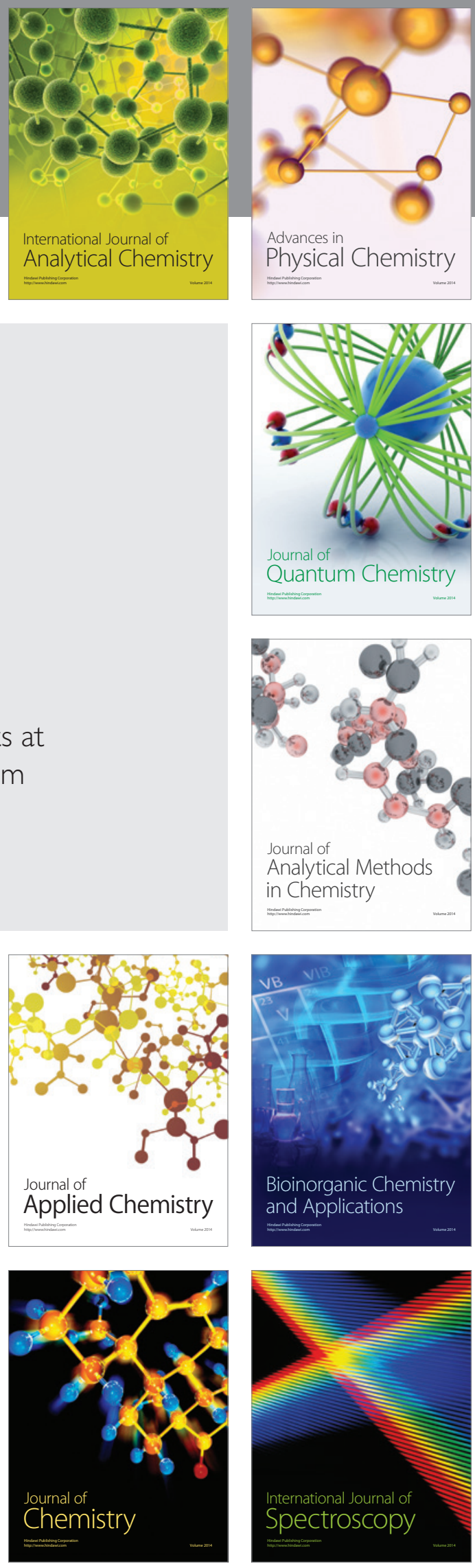